\title{
Why Real Citizens Would Turn to Artificial Leaders
}

\author{
NICOLAS SPATOLA, Center for Human Technologies, Istituto Italiano di Tecnologia, Genova, Italy \\ KARL F. MACDORMAN, School of Informatics and Computing, Indiana University, Indianapolis, \\ Indiana, USA
}

\begin{abstract}
Governments are increasingly using artificial intelligence to improve workflows and services. Applications range from predicting climate change, crime, and earthquakes to flu outbreaks, low air quality, and tax fraud. Artificial agents are already having an impact on eldercare, education, and open government, enabling users to complete procedures through a conversational interface. Whether replacing humans or assisting them, they are the technological fix of our times. In two experiments and a follow-up study, we investigate factors that influence the acceptance of artificial agents in positions of power, using attachment theory and disappointment theory as explanatory models. We found that when the state of the world provokes anxiety, citizens perceive artificial agents as a reliable proxy to replace human leaders. Moreover, people accept artificial agents as decision-makers in politics and security more willingly when they deem their leaders or government to be untrustworthy, disappointing, or immoral. Finally, we discuss these results with respect to theories of technology acceptance and the delegation of duties and prerogatives.
\end{abstract}

CCS Concepts: • Applied computing $\rightarrow$ E-government; • Human-centered computing $\rightarrow$ Empirical studies in HCI; • Computing methodologies $\rightarrow$ Cognitive science;

Additional Key Words and Phrases: Agents, artificial intelligence, attitudes, competence, technology acceptance, trust

ACM Reference format:

Nicolas Spatola and Karl F. MacDorman. 2021. Why Real Citizens Would Turn to Artificial Leaders. Digit. Gov.: Res. Pract. 2, 3, Article 26 (July 2021), 24 pages.

https://doi.org/10.1145/3447954

\section{INTRODUCTION}

Governments including China, the European Union, and the United States are increasingly using artificial agents (AA) to automate internal processes and provision services to the public [108]. However, a lack of their acceptance is a barrier to their integration into everyday life. Ordinary people's attitudes are ambivalent. They swing from hope that artificial agents will solve the world's problems [78] to fear of human obsolescence [79, 95] and loss of control [48]. In this context, would people be willing to give artificial agents roles as policymakers? Would they delegate their security to them, even at the risk of losing privacy? We examine whether artificial agents could be accepted as reliable proxies in political and security decision-making, thereby restoring trust in

Authors' addresses: N. Spatola, Center for Human Technologies, Istituto Italiano di Tecnologia, Genova, Italy; email: nicolas.spatola@iit.it; K. F. MacDorman, School of Informatics and Computing, Indiana University, Indianapolis, Indiana, USA; email: kmacdorm@indiana.edu. Updated Author Affiliation: Social Cognition in Human-Robot Interaction Laboratory, Italian Institute of Technology, Genova, Italy Nicolas Spatola Istituto Italiano di Tecnologia Social Cognition in Human-Robot Interaction via Enrico Melen 8316152 Genova, Italy.

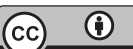

This work is licensed under a Creative Commons Attribution International 4.0 License.

(C) 2021 Copyright held by the owner/author(s).

2639-0175/2021/07-ART26

https://doi.org/10.1145/3447954

Digital Government: Research and Practice, Vol. 2, No. 3, Article 26. Publication date: July 2021. 
government. To do so, we build on two theories: attachment theory, which explains people's desire to restore a sense of security by relying on others, and disappointment theory, which explains their tendency to make choices to reduce future disappointment. We also probe the factors citizens use to compare artificial agents with humans in positions of power. More generally, we discuss the delegation of control to artificial agents.

Nonexperts typically consider artificial agents to be intelligent $[34,104]$ and able to reason $[50,110]$. Because of their perceived competence, they may be willing to rely on artificial agents more than on simple objects [45] or unreliable humans [55]. However, nonexperts also feel ambivalent about the future role of artificial agents in society. They especially worry about how their freedom and privacy could be maintained if artificial agents were in positions of power. Some people fear artificial agents taking over society, for example, because of their intelligence rapidly increasing above human levels after an event called the singularity [54]. Nevertheless, nonexperts simultaneously view artificial agents as a technological fix for labor shortages [9]. They accept them as human assistants or caregivers [42]. However, no study has investigated whether people could also accept artificial agents as political leaders or in other positions of power.

Beyond these futuristic scenarios, views on political leaders are evolving, as anxiety about the future rises, especially concerning trust. Here, trust is defined as citizens' confidence that political leaders will act in their shared interests. In many countries, citizens' trust in their leaders is in decline. This is exhibited by massive protests around the world [32]. Diminished trust is pushing citizens to seek nonpolitical alternatives [89]. Could these alternatives include artificial agents? To what extent does the acceptance of AAs in political roles depend on the current context, such as people's attitudes toward real human leaders?

In two experiments and a follow-up study, we explore these issues. To accomplish this, we first establish our two main theoretical frameworks: (1) attachment theory, wherein the acceptance of AAs in leadership roles is a means of restoring a sense of safety and control, and (2) disappointment theory, wherein the acceptance of AAs results from a lack of trust in political leaders and a search for alternatives.

Consistent with attachment theory, Experiment 1 revealed that, when the state of the world provokes anxiety, citizens view artificial agents more favorably, which increases their acceptance of them to replace human leaders in politics and security. Consistent with disappointment theory, the follow-up study revealed that individuals who distrust their government and other people are more inclined to view artificial agents as an alternative. Consistent with both theories, Experiment 2 revealed that, when citizens feel disappointed in government, they also view their political leaders as less moral, which causes them to trust them less. Viewing artificial agents as an alternative increases trust in having them in government. Our findings contribute to research on trust in artificial intelligence $[36,40,41,53,100]$ and the use of artificial intelligence in government $[21,47,108]$.

\subsection{Attitudes toward Artificial Agents and Trust}

The main factor enabling technology to become embedded in society is trust. Trust is key to technology acceptance and adoption [86], especially regarding people's beliefs about technology tools and their intention to use them [22]. The bases for trust in technology are performance, process, and purpose [63]. Performance is what technology does. Process is the degree to which it fits the situation and goal. Purpose is the degree to which it is used according to the owner's intent. Let us consider how artificial agents could earn our trust and reliance based on these three factors.

1.1.1 The Micro Level. Lee and Moray's model of trust in technology aligns with attachment theory [63]. Attachment theory ${ }^{1}$ describes within each individual a cognitive process: Attitudes toward others are partly shaped by a motivational and behavioral system that directs an individual who feels threatened to seek the protection of a trusted authority figure [50,76]. The core aspect of attachment theory is the search for physical or psychological proximity to the authority figure. For a young child, this would typically be a parent, though it could be a different caregiver, such as a relative or teacher. Attachment to the authority figure serves a purpose.

\footnotetext{
${ }^{1}$ This article assumes only the well supported cognitive process described by attachment theory, not its predictions about child development.

Digital Government: Research and Practice, Vol. 2, No. 3, Article 26. Publication date: July 2021.
} 
It heightens the individual's sense of security. An individual maturing into adulthood will seek new attachments that better serve this purpose. Shifts in attachment are driven by the expected performance of alternatives based on experience and other evidence of their reliability. Thus, the expectation of reliability serves as a basis for trust $[65,112]$.

In anxiety-provoking situations, an individual may restore a sense of security not only through attachment to another human being but also through attachment to a nonhuman object $[4,55,94]$. What remains unexplored is whether in these situations an artificial agent could be seen as a potential authority figure despite our ambivalence toward this form of technology.

People's confidence in their ability to control their environment and what happens to them is essential for their wellbeing. This process may be driven by biological and psychological necessity [64]. For the human species, relying on others is paradoxically one of the processes by which a feeling of control is maintained [31]. Our concept of others can broaden to include artificial agents; AAs, deemed socially viable, activate a socio-cognitive process similar to the one activated by humans $[103,104]$. Thus, attachment to an AA is plausible [29]. During uncertain times, when an individual's sense of control is threatened, attachment to artificial agents could restore it. AAs could act as a proxy for humans, because they tend to activate the same social scenarios. Indeed, AAs could enable people to feel safer [80]. The mere presence of the agent may give comfort even if it does not objectively restructure the situation.

1.1.2 The Macro Level. People typically lack direct control over the social and institutional conditions that affect their everyday lives. Their wellbeing, security, and other valued outcomes depend on a mediated form of agency: proxy agency. People use proxy agents-because of their expertise and resources-to act on their behalf for a specific purpose at an individual or societal level [5]. Could artificial agents be considered reliable proxy agents for a society? We would argue, yes. People already see technology as a potential fix for the world's problems, from climate change [17] to poverty [102]. Machines are increasingly used for medical diagnoses [74] and financial decisions [1]. The choice to rely on machines emerges from comparing their competence, efficiency, and reliability to those of humans. If we can delegate aspects of our health and finances to artificial agents, then why not politics? To answer this question, we must identify factors for comparing the perceived political efficacy of humans and machines.

\subsection{From Humans to Artificial Agents: The Trust Fix}

In many domains, people use proxy agents to ensure their security and wellbeing [5]. A political leader is a proxy agent, and trust is essential for citizens to agree to defer control. The effectiveness of government initiatives often depends on the trust of the citizenry. A decline in trust bodes ill for society [49].

Attitudes toward the government are not dichotomous, because a lack of trust in the government does not necessarily indicate distrust but rather a lack of information or conflicting information about its performance. Therefore, we consider trust in government to be a continuum, ranging from distrust to lack of trust to trust. Moreover, to conceptualize trust in government, we adopt the encapsulated view of trust that grounds it in the public's shared interests $[19,46]$. Trust is subjective. Different individuals have different ideas about what it means for political leaders to act in their shared interests and even which stakeholders share in those interests. Trust could arise from viewing the actions of political leaders as beneficial or from having confidence they will do what is right and fair [30].

Citizens tend to trust the government to act according to shared interests when the following apply: citizens believe organizational and political incentives limit government to its defined purpose; they are confident in its ability to serve that purpose; and the government is open and transparent enough for citizens to judge its performance. Citizens' trust also encourages those in government to act according to shared interests.

People can assess the performance, process, and purpose of their political leaders like they assess their technology. Performance is the degree to which their leaders are taking actions that produce valued outcomes. Process 
is the degree to which their leaders' decisions fit the situation, conform to the law, and follow the constitutional procedures that limit their power. Purpose is the degree to which their leaders govern in their citizens' interests. As no political leader or government can be approved unanimously, elections are organized.

Our contemporary era is marked by distrust in government in part because of the perceived gap between citizens and the political sphere. "One of the reasons for the political disintegration of recent years is the decline in the overall awareness of political action" [46]. If citizens feel disconnected from their government and its policies, when they do not like an outcome, they will be more likely to distrust their political leaders. As proxy agents, citizens would assess their leaders as unsatisfactory in adhering to their purpose and the process. Furthermore, citizens who are dissatisfied with policy decisions may feel voting in elections is not enough. Instead, they may protest, demand their leaders' replacement, and even try to get directly involved in government (e.g., Gilets faunes in France, Anti-ELAB in Hong Kong, and the 2019-2020 protests in Lebanon). Dissatisfaction and disconnection can be a source of anxiety, because the future seems less controllable. This perception motivates the search for reliable alternatives to restore a sense of control. Given today's political climate and the growing prevalence of artificial agents, it is timely to investigate how trust in government affects attitudes toward artificial agents, especially their capacity to serve in roles deemed poorly filled by current political leaders.

\subsection{The Present Experiments}

To consider these issues, we first investigate whether anxiety-provoking situations modulate attitudes toward artificial agents and their acceptance. Next, we examine how distrust of other people and the government influences the perception of artificial agents as an alternative to humans in political and security decision-making. We then investigate whether disappointment with governance modulates beliefs about political leaders' morality and relative evaluations of artificial agents. Finally, we propose an integrative model of how, and under what conditions, people could accept artificial agents as proxies for unreliable human leaders.

\section{GENERAL METHOD}

Experiment 1, a follow-up study, and Experiment 2 comprise the empirical part of this article.

\subsection{Recruitment and Sampling}

Participants were French speakers randomly selected from a roster of university students and recruited by email. Participation was voluntary. This study was carried out under the provisions of the Declaration of Helsinki.

\subsection{Procedure}

Materials were administered online via Qualtrics at a time and location chosen by the participant. All materials were presented in French.

On all questionnaires, participants responded to items on a 7-point scale. Unless otherwise noted, the scales indicated level of agreement from 1, "totally disagree," to 7, "totally agree." All dependent variables were indices that averaged scale items ranging from 1 to 7.

\subsection{Data Analysis}

Test statistics were two tailed and interpreted at a .05 significance level. Partial eta squared $\left(\eta_{\mathrm{p}}^{2}\right)$ was interpreted with small $=.01$, medium $=.06$, and large $=.14$ thresholds [23] and Cronbach's $\alpha$ with acceptable $=.7$, good $=.8$, and excellent $=.9$ thresholds. For the path analysis of the structural equation models, criteria for acceptable global fit were $p>.05$ for the model (cannot reject the exact fit hypothesis), RMSEA $\leq .05$ (a cutoff for good fit [72]), RMSEA $\hat{\varepsilon}_{\mathrm{L}}=0$ (confidence interval includes zero), and the combination rule: $\mathrm{CFI} \geq .95$ and SRMR $\leq .08$ [51]. All betas $(\beta)$ were standardized. ANOVAs were performed in SPSS. Mediation analyses used the PROCESS plugin.

Digital Government: Research and Practice, Vol. 2, No. 3, Article 26. Publication date: July 2021. 
Path analyses were performed in AMOS [58, 67, 114] by maximum likelihood (ML) estimation using the variance-covariance matrix [77]. ML estimation is widely used and often more reliable than other methods [14].

\section{EXPERIMENT 1: ATTITUDES MEDIATE ACCEPTANCE}

Experiment 1 presents news on the same topics at a low or high level of severity to manipulate anxiety provoked by the state of the world. The experiment is designed to investigate whether anxiety increases positive attitudes toward artificial agents and whether these attitudes mediate the acceptance of artificial agents in politics [84] and security positions [27] and willingness to trade freedom and privacy for the security they provide.

\subsection{Theory and Hypotheses}

Attachment theory predicts that, in an anxiety-provoking situation, individuals develop more positive attitudes toward new sources of protection that could restore their sense of safety [50]. These new sources could include artificial agents, which hold the promise of a technological fix $[18,54]$.

H1. Anxiety provoked by the state of the world increases positive attitudes toward artificial agents.

An anxiety-provoking situation can reinforce the basic need for control [7]. A feeling of control could be restored with nonhuman help [33], such as the help of artificial agents [35]. Attachment theory predicts that positive attitudes would motivate the acceptance of their protection. Thus, attitudes serve as a mediating variable.

H2. Anxiety increases the acceptance of artificial agents in politics and security, mediated by attitudes toward them.

Again, attachment theory predicts that, in an anxiety-provoking situation, an increase in positive attitudes toward artificial agents could mitigate the situation by encouraging citizens to enlist their help [35]. By extension, in the context of governance, positive attitudes should motivate willingness to delegate authority to artificial agents-even at the risk of losing some freedom and privacy.

H3. Anxiety increases willingness to trade freedom and privacy for the security provided by artificial agents, mediated by attitudes toward them.

Thus, in anxiety-provoking situations, in line with attachment theory, artificial agents could be seen as restoring a sense of safety or control by serving as a more reliable alternative to human leaders [52, 70].

\subsection{Research Design}

The experiment had a 2-group between-groups posttest-only design. Participants were randomly assigned to one of two conditions: anxiety-provoking or neutral.

\subsection{Procedure}

Participants were instructed to read a text, presented as a newspaper article, about the state of the world. The text included descriptions of the rise of extremism in Europe, the number of terrorist attacks in France, and the U.S. withdrawal from the 2015 Paris Agreement on climate change. ${ }^{2}$ After reading the text, participants were asked to complete questionnaires in the order listed below, except the order of the last two questionnaires was randomized.

\subsection{Independent Variable}

The independent variable was the state-of-the-world prime. In the anxiety-provoking condition, the text presented life as getting worse by heightening negative outcomes relative to the neutral condition. For example,

${ }^{2}$ The level of anxiety primed by the two texts was pretested with 20 participants. Participants responded to the question "Does this text makes me feel anxious?" on a 7-point scale from 1, "not at all," to 7, "totally." The anxiety-provoking text was rated more anxiety-provoking than the neutral text, $F(1,19)=23.35, p<.001, \eta_{\mathrm{p}}^{2}=.57$. The anxiety-provoking text was also rated more anxiety-provoking than the midpoint of the scale, $t(9)=4.64, p=.001, \eta_{\mathrm{p}}^{2}=.39$ while the neutral text was not, $t(9)=-2.09, p=.066, \eta_{\mathrm{p}}^{2}=.01$.

Digital Government: Research and Practice, Vol. 2, No. 3, Article 26. Publication date: July 2021. 
on terrorism, a sample text was "Ten attempted attacks have taken place in France since the beginning of the year, two of which left seven dead and 19 wounded," whereas, in the neutral condition, the corresponding text was "Ten attacks were successfully thwarted in France since the beginning of the year." On the environment, "Waters were 30 meters above normal and flooding was likely," whereas in the neutral condition, "Waters were nine meters above normal and flooding was possible." (In both conditions, an image showing the effect of rising waters in France accompanied the text.)

\subsection{Manipulation Check and Reactance Check}

To verify the effectiveness of the prime, participants answered the question, "What do you think the state of the world is today?" on a 7-point scale, ranging from 1, "totally negative," to 7, "totally positive."

To control for the level of coercion felt by participants in both the anxiety-provoking and neutral texts [91], the Shen and Dillard reactance questionnaire was administered [60, 99]. Reactance motivates individuals to restore their freedom. The Shen and Dillard questionnaire has two subscales: freedom threat (measured with items like "The message tried to make a decision for me," 4 items) and emotional threat (measured with items like "Did you feel angry while viewing this message?" 4 items).

\subsection{Dependent Variables}

3.6.1 Attitudes toward Artificial Agents. We adapted a scale from robotics to measure attitudes toward artificial agents $[83,87]$. Its subscales included items on AAs' future and social influence (e.g., "I feel that if I depend on artificial agents too much, something bad might happen," 5 items), relational attitudes (e.g., "I would feel uneasy if artificial agents had emotions," 5 items), and interactions and situations (e.g., "I would feel very nervous just standing in front of an artificial agent," 4 items). AAs were defined as "intelligent agents capable of analyzing their environment and processing a large amount of data to achieve goals (e.g., a robot or artificial intelligence agent)." The same definition was used in all experiments. This definition aligns with the dichotomy found between natural (e.g., humans, animals) and artificial agents (e.g., robot, artificial intelligence) [105].

For interpretability, items were scored so that higher values indicate a more positive attitude, which is the reverse of the original scale. The scale is the analogue of interpersonal warmth, the primary dimension of human social perception $[28,38]$, but tailored for human-AA interaction and the particular kinds of discomfort people have with artificial agents.

3.6.2 Acceptance of Artificial Agents in Politics and Security. Participants rated their level of acceptance of artificial agents as decision-makers in politics and security (measured with items like I would accept "using artificial agents to make political decisions" or "giving a veto to artificial agents when human decisions could be harmful," 3 items).

3.6.3 Willingness to Trade Freedom and Privacy. The last questionnaire was a surveillance-oriented security technologies scale adapted to measure willingness to trade freedom and privacy for the security provided by artificial agents [89]. (It included items like "Artificial agents should be able to store all data necessary to ensure safety for as long as necessary,” 5 items.)

\subsection{Results}

3.7.1 Participants. Overall, 227 participants completed the experiment $\left(M_{\text {age }}=22.91,66 \%\right.$ female, $\left.n=150\right)$. They were randomly assigned to one of two groups with 116 in the anxiety-provoking condition and 111 in the control condition.

3.7.2 Scale Reliability. The subscales $\left(\alpha_{1}=.57, \alpha_{2}=.18, \alpha_{3}=.57\right)$ of attitudes toward artificial agents were not reliable unless combined $(\alpha=.85)$. Thus, we treated them as a single measure throughout this article. The

Digital Government: Research and Practice, Vol. 2, No. 3, Article 26. Publication date: July 2021. 
Table 1. Descriptive Statistics (top) and Correlations (Bottom)

\begin{tabular}{lcccc}
\hline & $M$ & $S D$ & Skewness & Kurtosis \\
\hline Attitudes toward artificial agents & 4.55 & 1.22 & -0.33 & -0.37 \\
$\begin{array}{l}\text { Acceptance of artificial agents in politics } \\
\text { and security }\end{array}$ & 3.08 & 1.43 & 0.42 & -0.40 \\
$\begin{array}{l}\text { Willingness to trade freedom for the } \\
\text { security provided by AAs }\end{array}$ & 3.72 & 1.36 & 0.09 & -0.34 \\
\hline
\end{tabular}

\begin{tabular}{|c|c|c|c|}
\hline & & $\begin{array}{l}\text { Willingness to trade freedom for } \\
\text { the security provided by AAs }\end{array}$ & $\begin{array}{l}\text { Attitudes toward } \\
\text { artificial agents }\end{array}$ \\
\hline Acceptance of artificial agents & $r$ & .19 & .53 \\
\hline in politics and security & $p$ & .005 & $<.001$ \\
\hline Willingness to trade freedom for the & $r$ & & .29 \\
\hline security provided by AAs & $p$ & & $<.001$ \\
\hline
\end{tabular}

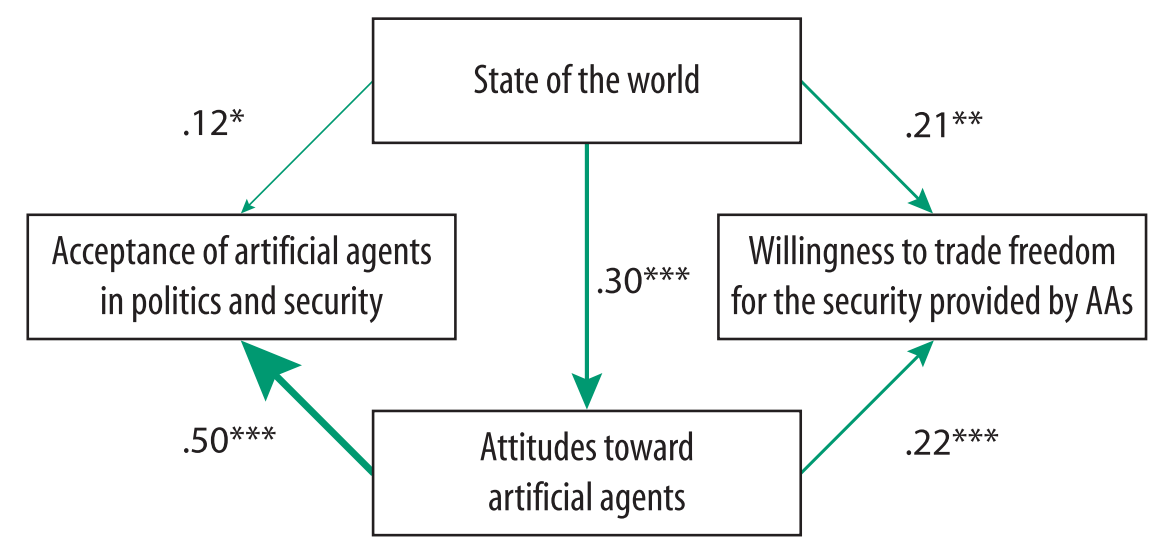

Fig. 1. Model 1 with attitudes toward artificial agents as a mediator of their acceptance.

following scales were all reliable: acceptance of artificial agents in politics and security $(\alpha=.70)$, willingness to trade freedom and privacy for the security provided by AAs $(\alpha=.86)$, freedom threat reactance $(\alpha=.81)$, and emotional threat reactance $(\alpha=.85)$. Descriptive statistics appear in Table 1.

3.7.3 Manipulation Check and Reactance Check. An ANOVA verified the effectiveness of the prime: The state of the world in the anxiety-provoking condition was rated as worse than in the neutral condition, $F(1,226)=$ $50.64, p<.001, \eta_{\mathrm{p}}^{2}=.18$. For both the anxiety-provoking condition, $t(115)=-18.41, p<.001, \eta_{\mathrm{p}}^{2}=.75$, and the neutral condition, $t(110)=-8.47, p<.001, \eta_{\mathrm{p}}^{2}=.39$, the state of the world was rated below the midpoint of the scale.

Both state-of-the-world primes were not significantly different in freedom threat, $F(1,226)=0.05, p=.815$, $\eta_{\mathrm{p}}^{2}<.01$, and emotional threat, $F(1,226)=2.71, p=.101, \eta_{\mathrm{p}}^{2}=.01$.

3.7.4 Model Selection. We evaluated the fit of two pathway models (Figures 1 and 2) to determine whether a participant's attitudes toward artificial agents was a mediator (Model 1) or a consequence (Model 2) of the acceptance of artificial agents in politics and security, controlling for direct effects. Attachment theory predicts attitudes as a mediator of acceptance. 


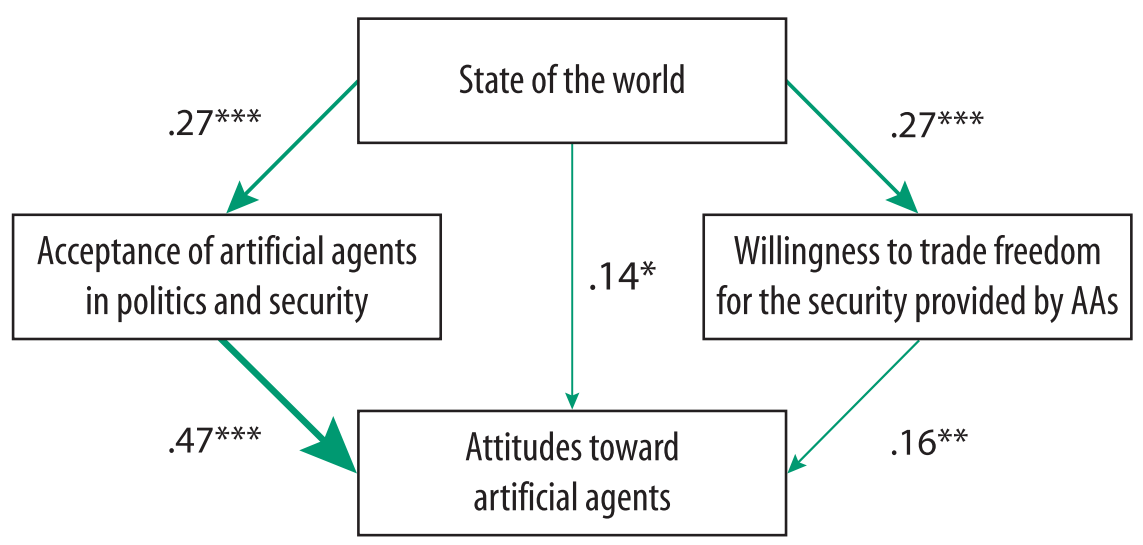

Fig. 2. Model 2 with attitudes toward artificial agents as a consequence of their acceptance.

Table 2. Model Fit Indices

\begin{tabular}{lcrcc}
\hline Indices & Indices & Model 1 & Model 2 & Threshold \\
\hline Absolute Indices & GFI & 1.000 & .992 & $\geq .95$ \\
& AGFI & .999 & .924 & $\geq .90$ \\
& RMR & .008 & .077 & \\
& SRMR & .004 & .040 & $\leq .08$ \\
& RMSEA & .000 & .104 & $\leq .05$ \\
\hline Incremental Indices & NFI & 1.000 & .973 & $\geq .95$ \\
& TLI & 1.045 & .881 & $\geq .95$ \\
& CFI & 1.000 & .980 & $\geq .95$ \\
\hline Parsimonious Indices & $\chi^{2} /$ df & 0.064 & 3.466 & $<3$ \\
& AIC & 18.064 & 21.466 & Smaller preferred \\
\hline
\end{tabular}

Note. Indices with unacceptable fit are shown in italics.

Model 1, which treated attitudes as a mediator rather than a consequence, had the best fit (Table 2). Only for this model were model fit indices fully accepted (e.g., $\chi^{2} / \mathrm{df}<3$; RMSEA $\leq .05$ ). Akaike information criterion (AIC), a measure of model quality [12], was also lower for Model 1 (18.064) than for Model 2 (21.466). The pathway models are considered different, because their AICs differ by more than 2 [20].

3.7.5 Hypothesis Testing. We conducted a mediation analysis to assess the reliability of the attachment model. Attitudes toward artificial agents were more favorable in the anxiety-provoking condition than in the neutral condition, $\left(a_{1}, a_{2}\right) t(225)=4.77, p<.001,95 \%$ CI $[.435,1.046]$. Thus, H1 was supported.

Controlling for the effect of attitudes toward artificial agents on the acceptance of artificial agents in politics and security, $\left(b_{1}\right) t(225)=8.49, p<.001,95 \% \mathrm{CI}[.447, .717]$, the direct effect of the condition on acceptance $\left(c_{1}\right)$ $t(225)=4.16, p<.001,95 \%$ CI $[.400,1.121]$ became nonsignificant $\left(c_{1}{ }^{\prime}\right) t(225)=1.87, p=.051,95 \%$ CI $[-.001, .660]$, indicating a mediation, $b=0.43,95 \% \mathrm{CI}[.240, .636]$ (Figure 3). Thus, $\mathrm{H} 2$ was supported.

Also considering the effect of attitudes on willingness to trade freedom for the security provided by artificial agents $\left(b_{2}\right) t(225)=3.39, p<.001,95 \%$ CI $[.104, .393]$, the direct effect of the condition on the acceptance of artificial agents in politics and security $\left(c_{2}\right) t(225)=4.26, p<.001,95 \% \mathrm{CI}[.400,1.088]$ decreased but remained significant $\left(c_{2}{ }^{\prime}\right) t(225)=3.13, p=.002,95 \%$ CI [.207, .913], indicating a partial mediation, $b=0.18,95 \%$ CI [.070, .331]. Thus, $\mathrm{H} 3$ was supported. 


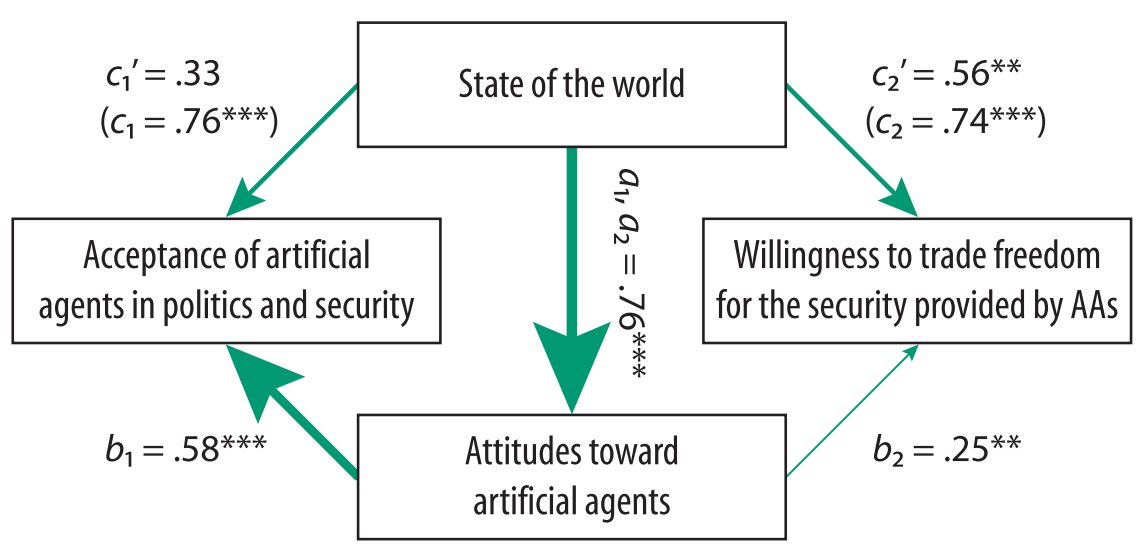

Fig. 3. The mediation model with attitudes toward artificial agents placed before acceptance.

\subsection{Discussion}

This experiment evaluated whether an anxiety-provoking state of the world could promote the acceptance of artificial agents in politics and security and even willingness to allow them to infringe on freedom and privacy. It also evaluated whether these effects were mediated by attitudes toward artificial agents.

The results showed that, in the anxiety-provoking condition, participants developed more favorable attitudes toward artificial agents, which increased their acceptance of them as proxies. These results are consistent with attachment theory, which posits that, in anxiety-provoking situations, people's need for control will increase; they will tend to develop positive attitudes about potential new sources of safety and as a consequence will consider them more reliable. Indeed, positive feelings toward humans or nonhumans heighten confidence in their ability to protect. In particular, like objects [4, 94], artificial agents are perceived as reliable and effectivefor example, if a person is disappointed by someone, they might develop attachment toward a transient object to restore their feeling of safety [55].

Delegation of control could, paradoxically, increase one's sense of control while reducing anxiety if the proxy is perceived as reliable and thus able to manage the situation more effectively and reliably. A sense of control is a basic psychological need [96]. This feeling could be elicited by the process described by attachment theory even when the attachment is to an artificial agent.

These results also show that contextual factors may lessen ambivalence about delegating control to artificial agents. Western societies often express ambivalence toward a new technology initially [73]. An anxietyprovoking context could make these technologies more appealing as a technological fix. Ambivalence would then subside as the technology becomes more prevalent. Historically, specific social and political contexts have helped or hindered the integration of technology in society $[66,82]$. They have led the scientific community [61, 62] and society as a whole [92] to accept or reject a particular innovation. The same forces could influence the acceptance of AAs in positions of power.

\section{FOLLOW-UP STUDY: FACTORS IMPROVING ATTITUDES TOWARD ARTIFICIAL AGENTS}

In line with attachment theory, Experiment 1 showed that an anxiety-provoking state of the world increased the acceptance of artificial agents in politics and security and that this effect was mediated by positive attitudes toward these artificial agents. What the experiment did not explain is why attitudes toward AAs should improve given that citizens already have a government to address threats. In this follow-up study, we seek to explain this by examining traits that might cause an individual to view artificial agents as a more reliable alternative to humans when making a direct comparison. Competence is the second dimension of human social perception, 
after interpersonal warmth $[28,38]$. While warmth reflects the intention to help or to harm, competence reflects the ability to act on that intention. Individuals may support replacing their human leaders with more competent and reliable AAs if they distrust their government and other people [43].

\subsection{Theory and Hypotheses}

We found an explanation of the positive shift in attitudes toward artificial agents in disappointment theory. Disappointment theory states that, if the outcome of a choice is worse than expected, disappointment reduces its perceived utility relative to other outcomes, which could cause the individual to make a different choice-even a worse choice-at the next opportunity $[68,69]$. Disappointed individuals tend to focus on alternative outcomes.

We extend disappointment theory to the realm of politics to explain why an individual would develop more positive attitudes toward artificial agents as part of a process of seeking alternatives to unreliable proxies. On our interpretation, disappointment theory would predict that an individual who perceives other people to be unreliable would seek alternative sources of safety from other humans and even from nonhumans [13, 76]. Nonhuman alternatives could include deities [71], inanimate objects [55], or artificial agents [35]. In line with attachment theory, individuals who feel disappointed by their government and other people might find artificial agents to be a more reliable alternative to restore their sense of control. Based on the results of Experiment 1, this process is enabled by developing positive attitudes toward these alternatives [76].

We propose that, when humans fail to offer a sense of security, artificial agents could be seen as an alternative that restores trust. Trust has been defined as "the willingness of a party to be vulnerable to the actions of another party based on the expectation that the other will perform a particular action important to the trustor, irrespective of the ability to monitor or control that other party" [98].

In this follow-up study, we examine whether individuals' attitudes toward artificial agents stem from a lack of trust in other people or in the government [57, 59]. In particular, we are interested in whether their attitudes are mediated by a process of direct comparison in the context of policy-making. Given that distrust of humans drives the search for alternative, nonhuman proxies, people who by disposition have a high level of interpersonal distrust would tend to view artificial agents as comparatively more reliable. These individuals who perceive artificial agents as a more reliable alternative to humans should also develop more positive attitudes toward them.

H4. Interpersonal distrust increases positive attitudes toward artificial agents, mediated by viewing artificial agents as an alternative to humans in political decision-making.

In line with disappointment theory, feelings of distrust in government could cause artificial agents to be viewed as a more reliable alternative to humans along various policy dimensions. Distrust in government should predict willingness to delegate roles to alternative proxy agents [57,59]. Artificial agents could then be perceived as trustworthy enough for a specific purpose like serving the common good when human political leaders are seen as unreliable.

H5. Trust in government decreases positive attitudes toward artificial agents, mediated by viewing artificial agents as an alternative to humans in political decision-making.

If distrust in political leaders may result in a search for alternatives, then, conversely, trust in leaders may reduce the likelihood of searching for alternatives and also the willingness to accept them. Therefore, satisfaction with the current government should engender less favorable attitudes toward artificial agents.

\subsection{Research Design}

This study on individual differences had a quantitative nonexperimental design.

\subsection{Procedure}

Participants were instructed to fill out different questionnaires. The questionnaires were presented in the following order: interpersonal distrust and trust in government in random order; artificial agents as an alternative to humans; and attitudes toward artificial agents and trust in governmental artificial agents in random order.

Digital Government: Research and Practice, Vol. 2, No. 3, Article 26. Publication date: July 2021. 


\subsection{Subject Variables}

4.4.1 Interpersonal Distrust. We used three items from the General Social Survey that evaluate interpersonal distrust-for example, "Do you think most people would try to take advantage of you if they got a chance?" (for a similar use, see Reference [16]). Participants responded using a 7-point scale, ranging from 1, "absolutely not," to 7, "absolutely yes."

4.4.2 Trust in Government. An adapted version of the trust in government measure from American National Election Studies was used to evaluate trust in the government [46]. (It was measured with items like "Do you think you can trust the government to make fair decisions?" 3 items.) Participants responded using a 7-point scale, ranging from 1 , "absolutely not," to 7 , "absolutely yes."

4.4.3 Artificial Agents as an Alternative to Humans. Participants were asked to assess the competence of both human political leaders and artificial agents to handle 15 issues, including the protection of humanity and the environment (e.g., ensuring the safety of citizens), public policy (e.g., making economic decisions), and the promotion of human rights (e.g., combating racism). Sample items included "Which is better at making economic decisions: humans or artificial agents?" For each issue, participants compared which entity, from 1, "humans," to 7, "artificial agents," would be most reliable to produce a positive result.

\subsubsection{Attitudes Toward Artificial Agents. This questionnaire was the same as in Experiment 1.}

4.4.5 Trust in Governmental Artificial Agents. A second version of the trust in government measure was used to evaluate participants' trust in governmental artificial agents (3 items).

\subsection{Results}

4.5.1 Participants. Overall, 303 participants completed the follow-up study (64\% female, $n=195, M_{\text {age }}=20.27$ ).

4.5.2 Scale Reliability. The following scales were all reliable: trust in government $(\alpha=.90)$, trust in governmental artificial agents $(\alpha=.82)$, interpersonal distrust $(\alpha=.70)$, attitudes toward artificial agents $(\alpha=.88)$, and artificial agents as an alternative to humans $(\alpha=.90)$. Descriptive statistics appear in Table 3.

4.5.3 Hypothesis Testing. A regression analysis revealed interpersonal distrust had a significant direct effect on attitudes toward artificial agents, $t(301)=3.95, p<.001,95 \% \mathrm{CI}[.139, .415]$ and a significant direct effect on artificial agents as an alternative to humans in political decision-making, $t(301)=2.65, p=.008,95 \% \mathrm{CI}[.041$, .277]. Controlling for the effect of artificial agents as an alternative to humans on attitudes toward artificial agents, $t(301)=9.66, p<.001,95 \% \mathrm{CI}[.454, .686]$, the direct effect of interpersonal distrust remained significant $t(301)=3.01, p=.003,95 \%$ CI $[.308, .064]$, indicating a partial mediation, $b=0.09,95 \%$ CI $[.023, .162]$. Thus, H4 was partially supported.

Trust in government had a nonsignificant positive direct effect on attitudes toward artificial agents, $t(301)=$ $-1.68, p=.095,95 \%$ CI $[-.209, .017]$, but a significant negative direct effect on artificial agents as an alternative to humans, $t(301)=-4.47, p<.001,95 \% \mathrm{CI}[-.303,-.118]$. Artificial agents as an alternative also predicted attitudes toward artificial agents, $t(301)=9.92, p<.001,95 \% \mathrm{CI}[.486, .726]$. Artificial agents as an alternative to humans mediated the effect of trust in government on attitudes toward artificial agents, $b=-0.13,95 \%$ CI [-.194, -.065$]$. Thus, H5 was supported.

4.5.4 Mediation Analysis. Interpersonal distrust had a significant positive direct effect on trust in governmental artificial agents, $t(301)=2.65, p=.008,95 \% \mathrm{CI}[.041, .277]$, and on artificial agents as an alternative to humans, $t(301)=2.65, p=.008,95 \% \mathrm{CI}[.041, .277]$. However, this effect was also mediated by artificial agents as an alternative to humans, $t(301)=10.86, p<.001,95 \% \mathrm{CI}[.539, .777]$. Controlling for this effect, the direct effect of interpersonal distrust on trust in governmental artificial agents became nonsignificant, $t(301)=0.95, p=.344$, $95 \%$ CI $[-.065, .186]$, indicating full mediation, $b=0.10,95 \%$ CI $[.028, .193]$. 
Table 3. Descriptive Statistics (top) and Correlations (Bottom)

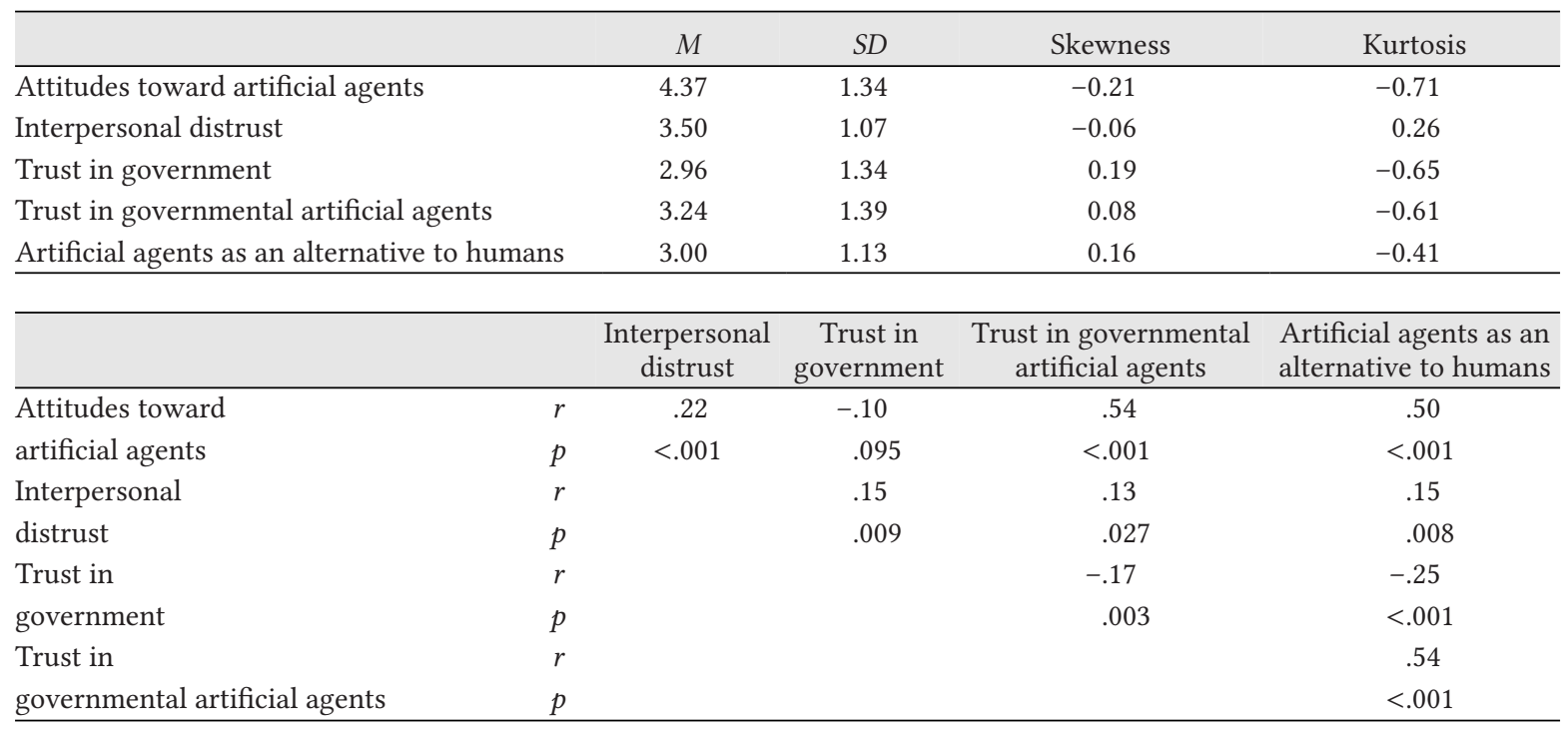

Table 4. Model Fit Indices

\begin{tabular}{lcr}
\hline Indices & Indices & Model \\
\hline Absolute Indices & GFI & 1.000 \\
& AGFI & 1.000 \\
& RMR & 0.001 \\
& SRMR & 0.001 \\
& RMSEA & .000 \\
\hline Incremental Indices & NFI & 1.000 \\
& TLI & 1.036 \\
& CFI & 1.000 \\
\hline Parsimonious Indices & $\chi^{2} / \mathrm{df}$ & 0.001 \\
& AIC & 28.001 \\
\hline
\end{tabular}

Trust in government had a negative direct effect on trust in governmental artificial agents, $t(301)=-3.00$, $p=.003,95 \%$ CI $[-.294,-.061]$. However, this effect was mediated by artificial agents as an alternative to humans, $t(301)=-4.47, p<.001,95 \%$ CI [-.303, -.118]. Controlling for this variable, $t(301)=10.58, p<.001,95 \%$ CI [.533, .777], the direct effect of trust in government on trust in governmental artificial agents became nonsignificant, $t(301)=-0.76, p=.449,95 \%$ CI $[-.142, .063]$, indicating a full mediation of trust in government on trust in governmental artificial agents, $b=-0.14,95 \% \mathrm{CI}[-.207,-.070]$.

4.5.5 Disappointment Model. We conducted a path analysis of the overall model controlling for the covariance between interpersonal distrust and trust in government [58]. The model was reliable according to fit thresholds [51]. Interpersonal distrust had a direct effect on attitudes toward artificial agents and an effect mediated by artificial agents as an alternative to humans; however, the effect of trust in government was mediated (Figure 4, Table 4).

Digital Government: Research and Practice, Vol. 2, No. 3, Article 26. Publication date: July 2021. 


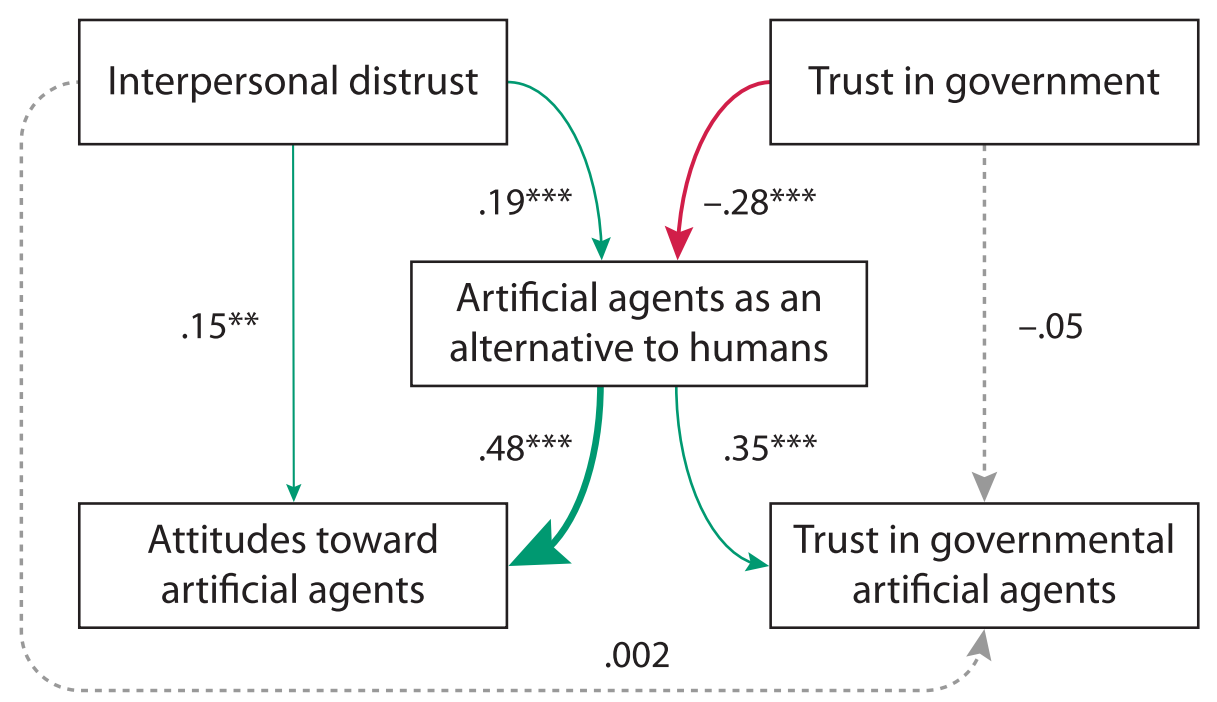

Fig. 4. The path model of attitudes toward artificial agents mediated by artificial agents as an alternative to humans as a function of the level of interpersonal distrust and governmental trust.

\subsection{Discussion}

The follow-up study supports disappointment theory as an explanation of why attitudes toward artificial agents became more positive in Experiment 1. Individuals who distrust other people and their government will view artificial agents as a more reliable alternative and thus will regard them more positively.

Perceiving artificial agents as a reliable proxy implies that they are judged to possess characteristics more suitable for effective decision-making than those possessed by humans. Paradoxically, individuals only agree to delegate duties to technology when they believe delegation will increase their sense of control [15]. The results also show that citizens will tend to accept artificial agents in positions of power when human leaders in those same positions are perceived as less reliable. Thus, the acceptance of artificial agents in positions of power depends on the context of alternatives. To better understand this process of comparing humans with artificial agents, we explore further the dimensions of this comparison, such as the perception of the leaders' morality.

\section{EXPERIMENT 2: FROM IMMORAL LEADERS TO ARTIFICIAL AGENTS}

Experiment 1 showed how attachment theory could be applied to artificial agents. An anxiety-provoking state of the world caused attitudes toward artificial agents to become more positive, which increased the acceptance of these agents in politics and security. The follow-up study showed how individuals who distrust their government and other people tended to view artificial agents as a reliable alternative and developed positive attitudes toward them. Building on disappointment theory, Experiment 2 investigates factors that explain why artificial agents in government are perceived as more reliable than humans.

\subsection{Theory and Hypotheses}

Political leaders are often assessed on their personal morality. Citizens may fear that political leaders mainly seek positions of power to attain high status [101], perhaps owing to narcissism [75, 88]. This cynical perspective could motivate the search for an incorruptible alternative, guided by logic rather than self-interest and not subject to monetary temptations [26, 75, 88, 101, 107]. Immoral leaders engender cynicism, a loss of trust in their actions, and fear of their consequences [8]. As mentioned earlier, disappointment theory predicts that the disappointment 
this loss of trust causes will motivate the acceptance of alternatives [46, 69]. Moreover, attachment theory predicts that a disappointing situation will motivate citizens to take action to restore their sense of control. In this case, they would be more likely to accept reliable alternatives as proxies. In delegating control to proxies, a calculation is made between the direct control lost and indirect control gained. The choice is not entirely rational, because disappointment inclines citizens to avoid the earlier choice that caused disappointment, even if the evidence still indicates it was the better choice.

In balance, the individual or group to whom control is delegated will be evaluated on dispositional criteria (e.g., the intention to help or harm) even before performance criteria (e.g., the ability to act on that intention). Thus, confidence in delegating authority depends not only on a proxy's competence but also on interpersonal warmth, the primary dimension of interpersonal perception; this trait will influence how performance, process, and purpose are judged $[28,38]$. Therefore, in a situation where an untrustworthy and immoral human proxy would be perceived as a source of anxiety, an artificial agent could be perceived as a more reliable external source of control. Under both conditions, there is a delegation of control. However, delegation to an artificial agent could be deemed less risky than to an unreliable human, assuming the AA would pursue the public interest governed only by logic.

Finally, in Experiment 2, we examine the factors underlying the hypothetical acceptance of artificial agents as a reliable alternative to untrustworthy political leaders. Decades of research in western democracies have shown that citizens attribute ever fewer moral qualities to their leaders [3, 93, 111]. This perception leads to a mistrust of government and a tendency to seek fresh alternatives [57, 107]. Indeed, as attributions of morality to the government decrease [90], artificial agents' lack of self-interest becomes more salient. Therefore, we hypothesized that, because trust traits are a major determinant of positive impressions of leaders [56, 113], those who perceive their government to be immoral and unreliable will view artificial agents as an acceptable alternative.

In Experiment 2, participants received either a disappointing or pleasing government prime. In the former condition, they described legislation they viewed negatively and, in the latter, legislation they viewed positively.

H6. Disappointment in the government decreases subsequent judgments of political leaders' morality.

H7. Disappointment in the government also decreases trust in government.

H8. Judging political leaders as less moral increases the perception of artificial agents as a reliable alternative to humans in political decision-making.

H9. The view of artificial agents as a reliable alternative increases trust in artificial agents.

These hypotheses align with disappointment theory, which predicts a devaluation of the prior choice that caused disappointment, namely, the election of current political leaders. The consequence of this devaluation is a search for alternatives and more favorable attitudes toward them. Therefore, AAs are likely to be seen as a trusted and reliable alternative.

The hypotheses also align with attachment theory, which predicts citizens are motivated to take actions to restore their sense of safety and control. In this context, that would entail restoring their feeling of trust in government through the adoption of artificial agents as proxies in place of morally suspect leaders.

\subsection{Research Design}

The experiment had a 2-group between-groups posttest-only design. Participants were randomly assigned to one of two conditions: pleasing government or disappointing government.

\subsection{Procedure}

Participants were asked to describe in one sentence negative or positive legislation ratified by their government. Next, they completed five questionnaires in the following order: political leaders' morality, trust in government, artificial agent's morality, artificial agents as an alternative to humans, and trust in governmental artificial agents.

Digital Government: Research and Practice, Vol. 2, No. 3, Article 26. Publication date: July 2021. 


\subsection{Independent Variable}

The independent variable was the disappointment prime. In the disappointing government condition, participants described legislation reflecting the incompetence of their government to challenge their confidence in the government (i.e., "In a few words, describe a reform or act for which you have questioned the competence of your government"). In the pleasing government condition, participants described legislation reflecting the competence of their government (i.e., "In a few words, describe a reform or an act for which you have praised the competence of your government").

\subsection{Dependent Variables}

5.5.1 Political Leaders' Morality. This questionnaire evaluated the perception of the government's morality with two subscales: morality and status seeking. (The former was measured with items like "Political leaders are willing to be unethical if they think it will help them succeed," 5 items, and the latter with items like "For political leaders, status indicates success in life," 5 items.) This questionnaire was an adaptation of the Machiavellian Personality Scale [24].

\subsubsection{Trust in Government. This questionnaire was the same as in the follow-up study.}

5.5.3 Artificial Agents as an Alternative to Humans. This questionnaire was the same as in the follow-up study.

5.5.4 Trust in Governmental Artificial Agents. This questionnaire was the same as in the follow-up study.

\subsection{Results}

5.6.1 Participants. Overall, 102 participants completed Experiment 2 ( $75 \%$ female, $n=76, M_{\text {age }}=22.42$ ). They were randomly assigned to two groups with 55 in the disappointing government condition and 47 in the pleasing government condition.

5.6.2 Scale Reliability. We confirmed the reliability of the scales: political leaders' morality $(\alpha=.87)$, trust in government $(\alpha=.88)$, trust in governmental artificial agents $(\alpha=.90)$, and artificial agents as an alternative to humans $(\alpha=.90)$. Descriptive statistics appear in Table 5 .

5.6.3 Manipulation Check. In both the disappointing and pleasing government conditions, legislation was described in 45 characters on average. To test the effect of the disappointment prime, a multivariate ANOVA was conducted with the experimental condition as the independent variable and all four measures as dependent variables.

The manipulation checks were successful: Political leaders were rated less moral in the disappointing government condition, $F(1,101)=18.29, p<.001, \eta_{\mathrm{p}}^{2}=.16$, and trust in government was rated lower, $F(1,101)=4.58$, $p=.035, \eta_{\mathrm{p}}^{2}=.04$, than in the pleasing government condition.

The prime had a nonsignificant direct effect on artificial agents' perceived morality, $F(1,101)=1.68, p=.198$, $\eta_{\mathrm{p}}^{2}=.02$, trust, $F(1,101)=3.31, p=.072, \eta_{\mathrm{p}}^{2}=.03$, and competence as an alternative to humans, $F(1,101)=0.98$, $p=.324, \eta_{\mathrm{p}}^{2}=.01$. Further analysis was required.

Interestingly, artificial agents were judged as more moral than political leaders in both the disappointing government condition, $F(1,100)=108.67, p<.001, \eta_{\mathrm{p}}^{2}=.52$, and the pleasing government condition, $F(1,100)=$ $17.08, p<.001, \eta_{\mathrm{p}}^{2}=.15$.

5.6.4 Hypothesis Testing. A mediation analysis was performed (Figure 5). ${ }^{3}$ The effect of the experimental condition on trust in government was mediated by the level of morality associated with political leaders,

\footnotetext{
${ }^{3}$ We controlled for the mediated model of the follow-up study: trust in government $\rightarrow$ artificial agents as an alternative to humans $\rightarrow$ trust in governmental artificial agents was still significant, $b=-0.17,95 \%$ CI $[-0.347,-0.007]$.
} 
Table 5. Descriptive Statistics with Mean and Standard Deviation (Top) and Correlation Matrix (Bottom)

\begin{tabular}{lcccc}
\hline & $M$ & $S D$ & Skewness & Kurtosis \\
\hline Political leaders' morality & 5.31 & 1.33 & -1.17 & 1.35 \\
$\begin{array}{l}\text { Artificial agents as an } \\
\text { alternative to humans }\end{array}$ & 3.41 & 1.19 & -0.07 & 0.35 \\
$\begin{array}{l}\text { Trust in government } \\
\text { Trust in governmental }\end{array}$ & 2.71 & 1.24 & 0.23 & -0.96 \\
artificial agents & 3.94 & 1.46 & -0.27 & 0.23 \\
\hline
\end{tabular}

\begin{tabular}{llccc}
\hline & & $\begin{array}{c}\text { Artificial agents as an } \\
\text { alternative to humans }\end{array}$ & $\begin{array}{c}\text { Trust in } \\
\text { government }\end{array}$ & $\begin{array}{c}\text { Trust in governmental } \\
\text { artificial agents }\end{array}$ \\
\hline Political leaders' morality & $r$ & .25 & -.35 & .14 \\
Artificial agents as an & $p$ & .010 & $<.001$ & .160 \\
alternative to humans & $r$ & & -.20 & .72 \\
Trust in government & $p$ & $r$ & .043 & $<.001$ \\
& $p$ & & & -.13 \\
\hline
\end{tabular}

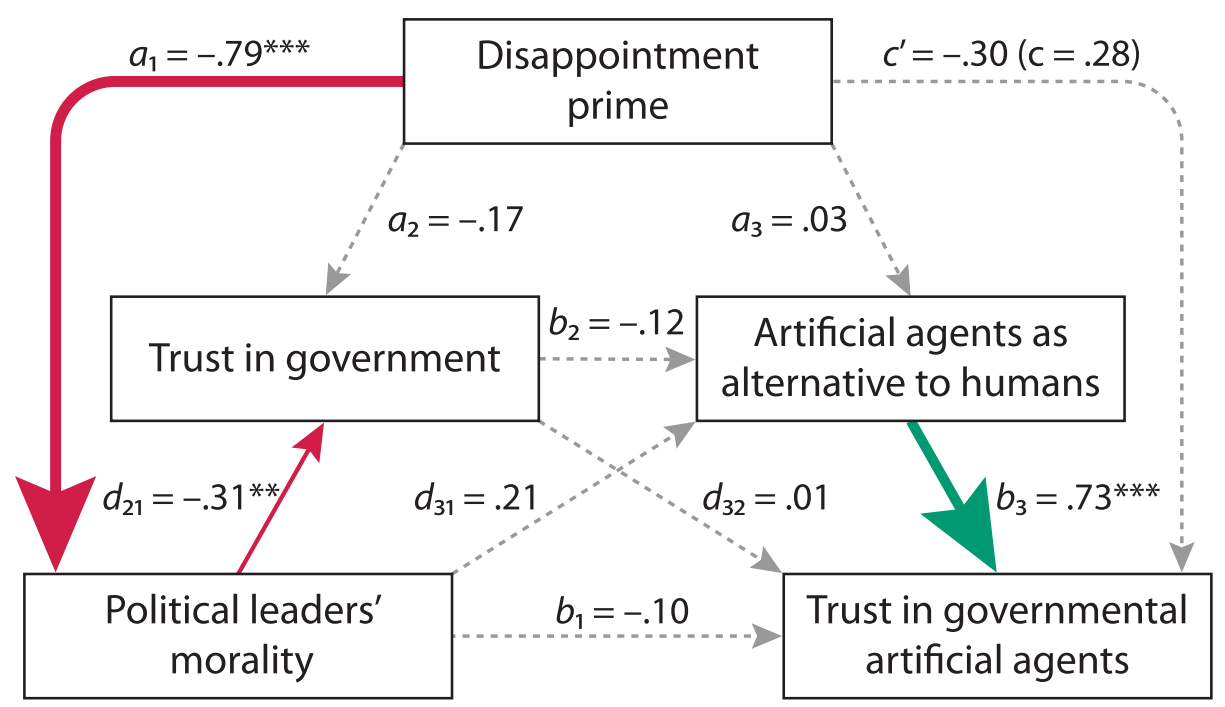

Fig. 5. The path model of perception of political leaders' morality as a function of the disappointment prime. In the disappointing government condition, participants evaluated their political leaders as less moral. This had a direct negative effect on trusting them in government. Viewing artificial agents as an alternative to humans also had a direct positive effect on trust in governmental artificial agents.

$\left(a_{1}\right) t(100)=-4.28, p<.001,95 \%$ CI $[-1.533,-0.562]$. In the disappointing government condition, less morality was attributed to political leaders. The less political leaders were seen as moral, the less trust was reported in government, $\left(d_{21}\right) t(100)=-3.06, p=.003,95 \%$ CI $[-0.480,-0.102]$. Thus, H6 and H7 were supported, though H7 was mediated.

Digital Government: Research and Practice, Vol. 2, No. 3, Article 26. Publication date: July 2021. 
Table 6. Model Fit Indices

\begin{tabular}{llr}
\hline Absolute Indices & GFI & .975 \\
& AGFI & .937 \\
& RMR & .061 \\
& SRMR & .049 \\
& RMSEA & .033 \\
\hline Incremental Indices & NFI & .943 \\
& TLI & .990 \\
& CFI & .994 \\
\hline Parsimonious Indices & $\chi 2 /$ df & 1.111 \\
& AIC & 24.664 \\
\hline
\end{tabular}

Controlling for trust in government, $\left(d_{32}\right) t(100)=-1.25, p=.215,95 \%$ CI $[-0.321,0.073]$, only political leaders' morality had an influence on artificial agents as a pleasing alternative to humans in political decision-making. A nonsignificant trend was that the less political leaders were seen as moral, the more artificial agents were viewed as an alternative, $\left(d_{32}\right) t(100)=1.94, p=.055,95 \%$ CI $[-0.004,0.387]$.

Finally, the more participants viewed artificial agents as an alternative, the more they reported trust in them, $\left(b_{3}\right) t(100)=10.11, p<.001,95 \%$ CI $[0.720,1.072]$. The best path to explain the model shows that less morality was attributed to the government in the disappointing government condition than in the pleasing government condition. As a consequence, artificial agents were more likely to be perceived as a pleasing alternative in this condition. This view was followed by an increase of trust in artificial agents, $b=0.18,95 \%$ CI [0.008, 0.434]. Thus, $\mathrm{H} 8$ and $\mathrm{H} 9$ was supported, though mediated.

We tested this theoretical model (Table 6). The model was reliable based on fit thresholds [51].

\subsection{Discussion}

Experiment 2 sought to determine whether the lack of morality of political leaders could explain the acceptance of artificial agents as proxies. The perceived lack of political leaders' morality increased the perception of artificial agents as a competent alternative in political decision-making, which was consistent with our hypothesis. This effect depended on disappointment in the government. Thus, participants who considered political leaders to be unreliable tended to be more accepting of artificial agents as an alternative, because they considered them more reliable and less prone to moral lapses. This result is reinforced by the fact that participants attributed fewer immoral traits to artificial agents than to their political leaders in both conditions. Artificial agents could, therefore, be considered as a technological solution to the failures of humans in addressing anxiety-provoking situations. This assertion remains speculative, and further studies are needed.

\subsection{Data Availability}

The dataset, scripts, and codebook for all analyses are available at https://osf.io/cg7nu/.

\section{GENERAL DISCUSSION}

We have shown that in an anxiety-provoking situation, attitudes toward artificial agents become more favorable, and people are more willing to accept them in politics and security (Experiment 1). They consider artificial agents as an alternative to humans in political decision-making because of a loss of trust in other people and in government (the follow-up study) and because disappointment in government calls political leader's morality into question (Experiment 2). This process can be linked to the intrinsic motivation of our species to reduce uncertainty, maintain a sense of control, and achieve this through proxy agents.

Digital Government: Research and Practice, Vol. 2, No. 3, Article 26. Publication date: July 2021. 
To examine our results in more detail, first consider the process of accepting an alternative as a proxy agent. In a given context, when people feel anxiety, this feeling will interfere with their ability to mitigate the negative impact of the situation $[44,85]$. To reduce the feeling, they become more willing to accept alternatives they might not otherwise have considered-for example, losing their freedom and privacy in exchange for the security provided by artificial agents [25]. The result is that artificial agents can be seen as a technological fix for a psychologically threatening situation.

This work supports the acceptance of AAs as reliable proxies based on attachment theory. In addition, in a political context, distrust in human proxies' willingness to perform a delegated function increases the perception of artificial agents as a more reliable alternative. This indicates that the identity of the agent, whether human or artificial, matters less than confidence it will perform as a proxy. It also shows that peoples' attitudes toward leaders are malleable, depending on the context (Experiment 1) or the state of their thoughts (Experiment 2). This observation echoes reports that people's increased interest in politics is largely superficial [10]. Thus, their opinions are likely to shift [2] with the deluge of information on politics [11].

The interaction between attachment theory, disappointment theory, and the technological fix may be viewed more broadly. The ambivalence that can be felt regarding the emergence of artificial agents in the human environment is often guided by representations-an imaginative process-rather than contextualized reflection-an iterative process [37]. When the evaluation of agents is contextualized, attitudes toward them become more positive as the result of comparing the advantages and disadvantages of relying artificial agents to fellow humans.

Functioning successfully in everyday life necessarily involves a reliance on proxy agents. People would be more willing to trust artificial agents in this role when they believe humans may act against their personal or shared interests [5]. Therefore, the conceptualized fear of being ruled by machines [81, 106] seems malleable, contextual [86], and likely to change [2]. Indeed, as nonexperts have a more abstract conception of artificial agents than human ones, they tend to attribute to them greater power over human life-both to do good and to do ill [105].

Therefore, our results could be integrated into the framework of the technology acceptance model (TAM) to explain how users accept and use a technology [109]. TAM posits that perceived usefulness and perceived ease of use drive attitudes toward technology and the intention to use it. In our study, perceived usefulness would be the main mediator that drives the acceptance of artificial agents [97]. The more the situation seems uncertain, or the more the humans in charge seem unreliable, the more suitable artificial agents would appear as replacements.

We propose that, as political leaders, artificial agents could be seen as more controllable and less inclined toward immoral and unethical behavior than humans. Again, as a psychological necessity, this could restore citizens' belief in their ability to exert control over the environment through a reliable proxy [64] and to reduce, in the context of government, the anxiety that comes from politically motivated decisions [39]. Indeed, the delegation of authority to representatives is motivated by the desire to make politics more effective. However, when a voter questions the effectiveness of the proxy, blame may be placed on the voter for choosing the wrong political leader. Thus, when a nonhuman proxy appears, an artificial agent that does not share human foibles, delegating political control to it may be considered a reasonable alternative. Artificial agents could, therefore, be seen as more reliable than humans, conforming to a fixed purpose without their own hidden agenda. In this way, the performance, process, and purpose of available proxy agents are compared, and artificial agents are evaluated more favorably.

More generally, these findings raise questions about the delegation of control to external systems and whether this delegation should be understood as a loss of control or as an outsourcing of control. If we delegate a hierarchical role to artificial agents, then does this mean that we are losing control over the corresponding activities or effectively managing them? For example, if we all agreed today to delegate the regulation of climate change laws around the globe to an artificial agent, does this mean we would lose control over climate change or increase our capacity to address it? This perspective of optimization could be the reason for favoring artificial agents over

Digital Government: Research and Practice, Vol. 2, No. 3, Article 26. Publication date: July 2021. 
humans when the latter seem unable to fulfill the objectives of their role as proxy agents. Therefore, the agents' reliability would be the deciding factor.

\subsection{Limitations and Future Work}

For the two experiments and the follow-up study, several limitations should be noted. First, they were prospective. Current reasoning about the potential role of artificial agents may differ from future reasoning about their actual acceptance in the real world. To assess this point, further studies must be conducted with a more ecologically valid methodology. Second, it is an open question whether the inclination of accept artificial agents is temporary, resulting only from current crises, or enduring.

Third, because we are investigating politics, the current situation is relevant, including the current political leadership and participants' political affiliations. We have not yet explored these dimensions. Replacing political leaders with artificial agents would be a challenging process. A preference for artificial agents could indicate a generalized opposition to elites.

Fourth, individual differences, such as age and socioeconomic status, as well as cultural differences, require investigation to determine the generalizability of our findings. These differences, in addition to an individual's attitudes toward artificial agents, might promote or inhibit the perception of their reliability [34]. Much evidence has accrued of culture being a moderating factor $[6,54,73]$. These potential factors raise general questions about decision-making processes, such as the integration of contextual, dispositional, and operational variables in weighing alternatives. They also raise two important issues, requiring further investigation: (1) how the designers of AAs, or the owners of this intellectual property, choose to have them personified, and (2) the extent to which their actions are accepted or rejected based on their personification.

Fifth, citizens must balance the assumption that artificial agents would make rational decisions in accord with shared interests and the possibility they could be programmed to serve other interests-or even be hacked. For example, if their goals were set by distrusted human leaders, they could be perceived with similar distrust.

To extend this research, it would be worthwhile to assess how people perceive actual decisions made by artificial agents versus those made by human leaders. Would people be willing to follow their policies, or would they be even more likely to protest against them? The extent to which citizens are informed about AAs and the transparency of their programming and goals would influence whether they are perceived as a reliable alternative to current political leaders in facing the same complex problems. Future studies could manipulate the effectiveness of the plans of an AA to determine how people react differently to the resulting positive and negative outcomes as compared with human political leaders.

\section{CONCLUSION}

Humans are increasingly integrating artificial agents into their environments. Despite this, people feel ambivalent about artificial agents in such roles as political leader or security provider, and further study is necessary to understand why this is the case. Beyond the study of artificial agents as an alternative to humans, we have found that a vision of the future, once considered dystopian, could be accepted to some extent. Depending on the context, points of comparison, and perceived effectiveness of the solution, humans will always tend toward solutions that allow them to reduce anxiety and restore safety and control. Of course, a disruptive phenomenon such as the introduction of AAs into government seems unsettling at first. But just consider that Benjamin Harrison, the first U.S. president to have electricity in the White House, never touched the switches for fear of electrocution. Thus, attitudes are bound to evolve. Already we base our decisions on algorithmic results that we often do not understand. We may be approaching an era in which people who follow paths determined by self-driving vehicles also follow policies designed by artificial agents.

Digital Government: Research and Practice, Vol. 2, No. 3, Article 26. Publication date: July 2021. 


\section{CONFLICT OF INTEREST}

The authors declare that the research was conducted in the absence of any commercial or financial relationships that could be construed as a potential conflict of interest.

\section{REFERENCES}

[1] Ajay Agrawal, Joshua Gans, and Avi Goldfarb. 2019. AI and International Trade. University of Chicago Press, Chicago. DOI: https: //doi.org/10.7208/chicago/9780226613475.003.0019

[2] Dolores Albarracin and Sharon Shavitt. 2018. Attitudes and attitude change. Ann. Rev. Psychol. DOI : https://doi.org/10.1146/annurevpsych-122216-011911

[3] Christopher J. Andersen and Yuliya V. Tverdova. 2003. Corruption, political allegiances, and attitudes toward government in contemporary democracies. Am. F. Pol. Sci 47, 1 (2003), 91-109. DOI: https://doi.org/10.1111/1540-5907.00007

[4] Eytan Bachar, Laura Canetti, Esti Galilee-Weisstub, Atara Kaplan-DeNour, and Arieh Y. Shalev. 1998. Childhood vs. adolescence transitional object attachment, and its relation to mental health and parental bonding. Child Psychiat. Hum. Dev. 28, 3 (1998), $149-167$. DOI : https://doi.org/10.1023/A:1022881726177

[5] Albert Bandura. 2018. Toward a psychology of human agency: Pathways and reflections. Perspect. Psychol. Sci, 13, 2 (2018), $130-136$. DOI : https://doi.org/10.1177/1745691617699280

[6] Christoph Bartneck, Tomohiro Suzuki, Takayuki Kanda, and Tatsuya Nomura. 2007. The influence of people's culture and prior experiences with Aibo on their attitude towards robots. AI Soc. 21, 1 (2007), 217-230. DOI : https://doi.org/10.1007/s00146-006-0052-7

[7] Roy F. Baumeister and Mark R. Leary. 1995. The need to belong: Desire for interpersonal attachments as a fundamental human motivation. Psychol. Bull. 117, 3 (1995), 497-529. DOI : https://doi.org/10.1037/0033-2909.117.3.497

[8] Jennifer A. H. Becker and H. Dan O’Hair. 2007. Machiavellians' motives in organizational citizenship behavior. F. Appl. Commun. Res. 35 (2007), 246-267. DOI : https://doi.org/10.1080/00909880701434232

[9] Tony Belpaeme, James Kennedy, Aditi Ramachandran, Brian Scassellati, and Fumihide Tanaka. 2018. Social robots for education: A review. Sci. Robot 3, 21 (2018), eaat5954. DOI : https://doi.org/10.1126/scirobotics.aat5954

[10] A. J. Berinsky. 2015. New Directions in Public Opinion. Routledge, London, UK.

[11] Adam J. Berinsky. 2012. New Directions in Public Opinion. Routledge, London, UK. DOI: https://doi.org/10.4324/9780203839836

[12] Herman J. Bierens. 2004. Information criteria and model selection. Retrieved from https://personal.psu.edu/hxb11/ INFORMATIONCRIT.PDF.

[13] Andreas Birgegard and Pehr Granqvist. 2004. The correspondence between attachment to parents and God: Three experiments using subliminal separation cues. Pers. Soc. Psychol. Bull. 30 (2004), 1122-1135. DOI : https://doi.org/10.1177/0146167204264266

[14] Kenneth A. Bollen. 1989. Structural Equations with Latent Variables. Wiley, New York, NY. DOI : https://doi.org/10.1002/9781118619179

[15] Éric Brangier and Sonia Hammes-Adelé. 2011. Beyond the technology acceptance model: Elements to validate the human-technology symbiosis model. In Lecture Notes in Computer Science (Including Subseries Lecture Notes in Artificial Intelligence and Lecture Notes in Bioinformatics), 13-21. DOI : https://doi.org/10.1007/978-3-642-21716-6_2

[16] John Brehm and Wendy Rahn. 1997. Individual-level evidence for the causes and consequences of social capital. Am. F. Pol. Sci 41, 3 (1997), 999-1023. DOI : https://doi.org/10.2307/2111684

[17] Peter G. Brewer. 2007. Evaluating a technological fix for climate. Proc. Natl. Acad. Sci. U.S.A. 104, 24 (2007), 9915-9916. DOI : https: //doi.org/10.1073/pnas.0703892104

[18] E. Broadbent, R. Stafford, and B. MacDonald. 2009. Acceptance of healthcare robots for the older population: Review and future directions. Int. F. Soc. Robot. 1 (2009), 319-330. DOI : https://doi.org/10.1007/s12369-009-0030-6

[19] Christian Budnik. 2018. Trust, reliance, and democracy. Int. F. Philos. Stud, 26, 2 (2018), 221-239. DOI : https://doi.org/10.1080/09672559. 2018.1450082

[20] Kenneth P. Burnham and David R. Anderson. 2004. Multimodel inference: Understanding AIC and BIC in model selection. Sociol. Methods Res. 33 (2004), 261-304. DOI : https://doi.org/10.1177/0049124104268644

[21] James Butcher and Irakli Beridze. 2019. What is the state of artificial intelligence governance globally? RUSI f. 164, 5-6 (2019), 88-96. DOI : https://doi.org/10.1080/03071847.2019.1694260

[22] Lemuria Carter and France Bélanger. 2005. The utilization of e-government services: Citizen trust, innovation and acceptance factors. Inf. Syst. F. 15, 1 (2005), 5-25. DOI: https://doi.org/10.1111/j.1365-2575.2005.00183.x

[23] Jacob Cohen. 1973. Eta-squared and partial eta-squared in fixed factor ANOVA designs. Educ. Psychol. Meas. 33, 1 (1973), $107-112$. DOI : https://doi.org/10.1177/001316447303300111

[24] Jason J. Dahling, Brian G. Whitaker, and Paul E. Levy. 2009. The development and validation of a new Machiavellianism scale. F. Manage. 35, 2 (2009), 219-257. DOI : https://doi.org/10.1177/0149206308318618

[25] Darren W. Davis and Brian D. Silver. 2004. Civil liberties vs. security: public opinion in the context of the terrorist attacks on America. Am. F. Pol. Sci. 48 (2004), 28-46. DOI : https://doi.org/10.1111/j.0092-5853.2004.00054.x

Digital Government: Research and Practice, Vol. 2, No. 3, Article 26. Publication date: July 2021. 
[26] Walter D. Davis and William L. Gardner. 2004. Perceptions of politics and organizational cynicism: An attributional and leader-member exchange perspective. Leader. Quart. 15 (2004), 439-465. DOI : https://doi.org/10.1016/j.leaqua.2004.05.002

[27] Tamara Denning, Cynthia Matuszek, Karl Koscher, Joshua R. Smith, and Tadayoshi Kohno. 2009. A spotlight on security and privacy risks with future household robots: Attacks and lessons. In Proceedings of the ACM International Conference Proceeding Series, 105-114. DOI : https://doi.org/10.1145/1620545.1620564

[28] Cydney H. Dupree and Susan T. Fiske. 2017. Universal dimensions of social signals: Warmth and competence. In Social Signal Processing. 23-33. DOI: https://doi.org/10.1017/9781316676202.003

[29] Michał Dziergwa, Mirela Kaczmarek, Paweł Kaczmarek, Jan Kędzierski, and Karolina Wadas-Szydłowska. 2018. Long-term cohabitation with a social robot: A case study of the influence of human attachment patterns. Int. J. Soc. Robot 10, 1 (2018), $163-176$. DOI : https://doi.org/10.1007/s12369-017-0439-2

[30] David Easton. 1957. An approach to the analysis of political systems. World Politics 9, 3 (1957), 383-400. DOI: https://doi.org/10.2307/ 2008920

[31] Kathleen O. Ell, Joanne E. Mantell, Maurice B. Haraovitch, and Robert H. Nishimoto. 1989. Social support, sense of control, and coping among patients with breast, lung, or colorectal cancer. F. Psychosoc. Oncol. 7, 3 (1989), 63-89. DOI: https://doi.org/10.1300/ J077v07n03_05

[32] Gunn Enli and Linda Therese Rosenberg. 2018. Trust in the age of social media: Populist politicians seem more authentic. Soc. Media Soc. 4, 1 (2018), 1-11. DOI : https://doi.org/10.1177/2056305118764430

[33] Nicholas Epley, Scott Akalis, Adam Waytz, and John T. Cacioppo. 2008. Creating social connection through inferential reproduction: Loneliness and perceived agency in gadgets, gods, and greyhounds. Psychol. Sci. 19, 2 (2008), 114-120. DOI: https://doi.org/10.1111/j. 1467-9280.2008.02056.x

[34] Nicholas Epley, Adam Waytz, and John T. Cacioppo. 2007. On seeing human: A three-factor theory of anthropomorphism. Psychol. Rev. 114, 4 (2007), 864-886. DOI : https://doi.org/10.1037/0033-295X.114.4.864

[35] Friederike Eyssel and Natalia Reich. 2013. Loneliness makes the heart grow fonder (of robots) - On the effects of loneliness on psychological anthropomorphism. In Proceedings of the ACM/IEEE International Conference on Human-Robot Interaction, 121-122. DOI : https://doi.org/10.1109/HRI.2013.6483531

[36] Andrea Ferrario, Michele Loi, and Eleonora Viganò. 2020. In AI we trust incrementally: a multi-layer model of trust to analyze humanartificial intelligence interactions. Philos. Technol. 33, 3 (2020), 523-539. DOI : https://doi.org/10.1007/s13347-019-00378-3

[37] John Andrew Fisher. 1991. Disambiguating anthropomorphism: An interdisciplinary review. Perspect. Ethol. 9 (1991), 49-85.

[38] Susan T. Fiske, Amy J. C. Cuddy, and Peter Glick. 2007. Universal dimensions of social cognition: Warmth and competence. Trends Cogn. Sci. 11, 2 (2007), 77-83. DOI : https://doi.org/10.1016/j.tics.2006.11.005

[39] Ann Gillard and Mark F. Roark. 2013. Older adolescents' self-determined motivations to disclose their HIV status. In fournal of Child and Family Studies. 672-683. DOI: https://doi.org/10.1007/s10826-012-9620-2

[40] Omri Gillath, Ting Ai, Michael Branicky, Shawn Keshmiri, Rob Davison, and Ryan Spaulding. 2021. Attachment and trust in artificial intelligence. Comput. Hum. Behav. 115 (2021). DOI : https://doi.org/10.1016/j.chb.2020.106607

[41] Ella Glikson and Anita Williams Woolley. 2020. Human trust in artificial intelligence: Review of empirical research. Acad. Manag. Ann. 14, 2 (2020), 627-660. DOI : https://doi.org/10.5465/annals.2018.0057

[42] Jennifer Goetz and Sara Kiesler. 2002. Cooperation with a robotic assistant. In Proceedings of the Conference on Human Factors in Computing Systems. 578-579. DOI: https://doi.org/10.1145/506486.506492

[43] Paul Goren. 2005. Party identification and core political values. Am. F. Pol. Sci. 49, 4 (2005), 881-896. DOI: https://doi.org/10.1111/j. 1540-5907.2005.00161.x

[44] Dan W. Grupe and Jack B. Nitschke. 2013. Uncertainty and anticipation in anxiety: An integrated neurobiological and psychological perspective. Nat. Rev. Neurosci. 14 (2013), 488-501. DOI : https://doi.org/10.1038/nrn3524

[45] Peter A. Hancock, Deborah R. Billings, Kristin E. Schaefer, Jessie Y. C. Chen, Ewart J. De Visser, and Raja Parasuraman. 2011. A meta-analysis of factors affecting trust in human-robot interaction. Hum. Fact. 53, 5 (2011), 517-527. DOI: https://doi.org/10.1177/ 0018720811417254

[46] Russell Hardin. 2013. Government without trust. f. Trust Res. 3, 1 (2013), 32-52. DOI : https://doi.org/10.1080/21515581.2013.771502

[47] Teresa M. Harrison and Luis Felipe Luna-Reyes. 2020. Cultivating trustworthy artificial intelligence in digital government. (unpublished). DOI : https://doi.org/10.1177/0894439320980122

[48] Dirk Helbing, Bruno S. Frey, Gerd Gigerenzer, Ernst Hafen, Michael Hagner, Yvonne Hofstetter, Jeroen Van Den Hoven, Roberto V. Zicari, and Andrej Zwitter. 2018. Will democracy survive big data and artificial intelligence? In Towards Digital Enlightenment: Essays on the Dark and Light Sides of the Digital Revolution. Springer, Cham, 73-98. DOI : https://doi.org/10.1007/978-3-319-90869-4_7

[49] Sören Holmberg, Bo Rothstein, and Naghmeh Nasiritousi. 2009. Quality of government: What you get. Annu. Rev. Polit. Sci. 12 (2009), 135-61. DOI: https://doi.org/10.1146/annurev-polisci-100608-104510

[50] David Howe. 2009. Handbook of Attachment: Theory, Research and Clinical Applications. Rough Guides, London, UK. DOI : https://doi. org/10.1177/1468017309342543

Digital Government: Research and Practice, Vol. 2, No. 3, Article 26. Publication date: July 2021. 
[51] Li Tze Hu and Peter M. Bentler. 1999. Cutoff criteria for fit indexes in covariance structure analysis: Conventional criteria versus new alternatives. Struct. Equ. Model 6, 1 (1999), 1-55. DOI : https://doi.org/10.1080/10705519909540118

[52] Tobin Im, Wonhyuk Cho, Greg Porumbescu, and Jungho Park. 2014. Internet, trust in government, and citizen compliance. f. Public Adm. Res. Theory 24, 3 (2014), 741-763. DOI : https://doi.org/10.1093/jopart/mus037

[53] Alon Jacovi, Ana Marasović, Tim Miller, and Yoav Goldberg. 2021. Formalizing trust in artificial intelligence: Prerequisites, causes and goals of human trust in AI. In Proceedings of the 2021 ACM Conference on Fairness, Accountability, and Transparency, 624-635. https://doi.org/10.1145/3442188.3445923

[54] Frédéric Kaplan. 2004. Who is afraid of the humanoid? Investigating cultural differences in the acceptance of robots. Int. F. Humanoid Robot. 1, 3 (2004), 465-480. DOI : https://doi.org/10.1142/s0219843604000289

[55] Lucas A. Keefer, Mark J. Landau, Zachary K. Rothschild, and Daniel Sullivan. 2012. Attachment to objects as compensation for close others' perceived unreliability. F. Exp. Soc. Psychol. 48, 4 (2012), 912-917. DOI : https://doi.org/10.1016/j.jesp.2012.02.007

[56] Donald R. Kinder, Mark D. Peters, Robert P. Abelson, and Susan T. Fiske. 1980. Presidential prototypes. Polit. Behav. 2, 4 (1980), 315 -337. DOI : https://doi.org/10.1007/BF00990172

[57] David C. King. 1997. Why People Don't Trust Government. Harvard University Press, Cambridge, MA.

[58] Rex B. Kline. 2015. Principles and Practice of Structural Equation Modeling. Guilford, New York, NY. DOI : https://doi.org/10.15353/cgjscrcessc.v1i1.25

[59] Roderick M. Kramer. 1999. Trust and distrust in organizations: Emerging perspectives, enduring questions. Annu. Rev. Psychol. 50, 1 (1999), 569-598. DOI : https://doi.org/10.1146/annurev.psych.50.1.569

[60] Göran Larsson. 2014. Textbooks and critical readings-A challenge for the future: A brief response to Emanuelsson and Ramey. Method Theory Study Relig. 26, 3 (2014), 308-314. DOI : https://doi.org/10.1163/15700682-12341325

[61] Edwin Layton. 1971. Mirror-image twins: The communities of science and technology in 19th-century America. Technol. Cult. 12, 4 (1971), 562-580. DOI : https://doi.org/10.2307/3102571

[62] Edwin T. Layton. 1976. American ideologies of science and engineering. Technol. Cult. 17, 4 (1976), 688-701. DOI: https://doi.org/10. $2307 / 3103675$

[63] John Lee and Neville Moray. 1992. Trust, control strategies and allocation of function in human-machine systems. Ergonomics 35,10 (1992), 1243-1270. DOI : https://doi.org/10.1080/00140139208967392

[64] Lauren A. Leotti, Sheena S. Iyengar, and Kevin N. Ochsner. 2010. Born to choose: The origins and value of the need for control. Trends Cogn. Sci. 14 (2010), 457-463. DOI : https://doi.org/10.1016/j.tics.2010.08.001

[65] J. David Lewis and Andrew Weigert. 1985. Trust as a social reality. Soc. Forces 63, 4 (1985), 967-985. DOI : https://doi.org/10.1093/sf/63. 4.967

[66] Loet Leydesdorff and Girma Zawdie. 2010. The triple helix perspective of innovation systems. Technol. Anal. Strateg. Manage. 22 (2010), 789-804. DOI : https://doi.org/10.1080/09537325.2010.511142

[67] John C. Loehlin and A. Alexander Beaujean. 2016. Latent Variable Models: An Introduction to Factor, Path, and Structural Equation Analysis, 5th edition. Taylor \& Francis, London, UK. DOI : https://doi.org/10.4324/9781315643199

[68] Graham Loomes and Robert Sugden. 1982. Regret theory: An alternative theory of rational choice under uncertainty. Econ. 7. 92, 368 (1982), 805-824. DOI : https://doi.org/10.2307/2232669

[69] Graham Loomes and Robert Sugden. 1986. Disappointment and dynamic consistency in choice under uncertainty. Rev. Econ. Stud. 53, 2 (1986), 271-282. DOI : https://doi.org/10.2307/2297651

[70] Richard Loudon. 2002. Trust in government. Commun. Dev. F. 37 (2002), 118-119. DOI : https://doi.org/10.1093/cdj/37.1.118

[71] Fadi T. Maalouf, Giovanna Porta, Benedetto Vitiello, Graham Emslie, Taryn Mayes, Gregory Clarke, Karen D. Wagner, Joan Rosenbaum Asarnow, Anthony Spirito, Martin Keller, Boris Birmaher, Neal Ryan, Wael Shamseddeen, Satish Iyengar, and David Brent. 2012. Do sub-syndromal manic symptoms influence outcome in treatment resistant depression in adolescents? A latent class analysis from the TORDIA study. F. Affect. Disord. 138, 1-2 (2012), 86-95. DOI : https://doi.org/10.1016/j.jad.2011.12.021

[72] Robert C. MacCallum, Michael W. Browne, and Hazuki M. Sugawara. 1996. Power analysis and determination of sample size for covariance structure modeling. Psychol. Methods 1, 2 (1996), 130-149. DOI : https://doi.org/10.1037/1082-989X.1.2.130

[73] Karl F. MacDorman, Sandosh K. Vasudevan, and Chin Chang Ho. 2009. Does Japan really have robot mania? Comparing attitudes by implicit and explicit measures. AI Soc. 23, 4 (2009), 485-510. DOI : https://doi.org/10.1007/s00146-008-0181-2

[74] Thomas M. Maddox, John S. Rumsfeld, and Philip R. O. Payne. 2019. Questions for artificial intelligence in health care. F. Am. Med. 321 (2019), 31-32. DOI : https://doi.org/10.1001/jama.2018.18932

[75] John W. McHoskey, William Worzel, and Christopher Szyarto. 1998. Machiavellianism and psychopathy. F. Pers. Soc. Psychol. 74, 1 (1998), 192-210. DOI : https://doi.org/10.1037/0022-3514.74.1.192

[76] Mario Mikulincer, Phillip R. Shaver, and Dana Pereg. 2003. Attachment theory and affect regulation: The dynamics, development, and cognitive consequences of attachment-related strategies. Motivat. Emot. 27 (2003), 77-102. DOI : https://doi.org/10.1023/A: 1024515519160

[77] Manit Mishra. 2016. Confirmatory factor analysis (CFA) as an analytical technique to assess measurement error in survey research. Paradigm 20, 2 (2016), 97-112. DOI : https://doi.org/10.1177/0971890716672933

Digital Government: Research and Practice, Vol. 2, No. 3, Article 26. Publication date: July 2021. 
[78] Evgeny Morozov. 2014. To Save Everything, Click Here: Technology, Solutionism and the Urge to Fix Problems That Don't Exist. Penguin Books Ltd, London, UK. DOI : https://doi.org/10.3233/ip-130311

[79] Taewoo Nam. 2019. Citizen attitudes about job replacement by robotic automation. Futures 109, (2019), 39-49. DOI: https://doi.org/10. 1016/j.futures.2019.04.005

[80] Clifford Nass and Youngme Moon. 2000. Machines and mindlessness: Social responses to computers. J. Soc. Issues 56, 1 (2000), 81-103. DOI : https://doi.org/10.1111/0022-4537.00153

[81] Andrew J. Nathan and Andrew Scobell. 2012. How China sees America. Foreign Aff. 91, 5 (2012), 557-573.

[82] Richard R. Nelson. 1994. The co-evolution of technology, industrial structure, and supporting institutions. Ind. Corp. Chang. 3, 1 (1994), 47-63. DOI : https://doi.org/10.1093/icc/3.1.47

[83] Tatsuya Nomura, Tomohiro Suzuki, Takayuki Kanda, and Kensuke Kato. 2006. Measurement of anxiety toward robots. In Proceedings of the IEEE International Workshop on Robot and Human Interactive Communication, 372-377. DOI : https://doi.org/10.1109/ROMAN. 2006.314462

[84] Seri Nonaka, Kenji Inoue, Tatsuo Arai, and Yasushi Mae. 2004. Evaluation of human sense of security for coexisting robots using virtual reality evaluation of pick and place motion of humanoid robots. In Proceedings of the IEEE International Conference on Robotics and Automation, 2770-2775. DOI : https://doi.org/10.1109/robot.2004.1307480

[85] Hadas Okon-Singer. 2018. The role of attention bias to threat in anxiety: Mechanisms, modulators and open questions. Curr. Opin. Behav. Sci. 19 (2018), 26-30. DOI : https://doi.org/10.1016/j.cobeha.2017.09.008

[86] Raja Parasuraman, Thomas B. Sheridan, and Christopher D. Wickens. 2008. Situation Awareness, Mental Workload, and Trust in awareness, mental workload, and trust in automation: Viable, empirically supported cognitive engineering constructs. f. Cogn. Eng. Decis. Mak 2, 2 (2008), 140-160. DOI : https://doi.org/10.1518/155534308X284417

[87] Camille Parmesan. 2006. Ecological and evolutionary responses to recent climate change. Annu. Rev. Ecol. Evol. Syst. 37, (2006) 637-669. DOI : https://doi.org/10.2307/annurev.ecolsys.37.091305.30000024

[88] Delroy L. Paulhus and Kevin M. Williams. 2002. The dark triad of personality: Narcissism, Machiavellianism, and psychopathy. F. Res. Pers 36, 6 (2002), 556-563. DOI : https://doi.org/10.1016/S0092-6566(02)00505-6

[89] Vincenzo Pavone and Sara Degli Esposti. 2012. Public assessment of new surveillance-oriented security technologies: Beyond the trade-off between privacy and security. Publ. Underst. Sci. 21, 5 (2012), 556-572. DOI : https://doi.org/10.1177/0963662510376886

[90] Miroslav Popper. 2013. Social trust, norms and morality. Hum. Aff. 23, 3 (2013), 443-457. DOI : https://doi.org/10.2478/s13374-0130140-6

[91] Brian L. Quick. 2012. What is the best measure of psychological reactance? An empirical test of two measures. Health Commun. 27, 1 (2012), 1-9. DOI : https://doi.org/10.1080/10410236.2011.567446

[92] Peter J. Richerson and Morten Christiansen. 2013. Cultural Evolution: Society, Technology, Language, and Religion. MIT Press, Cambridge, MA.

[93] Bo Rothstein and Daniel Eek. 2009. Political corruption and social trust: An experimental approach. Ration. Soc. 21, 1 (2009), 81-112. DOI : https://doi.org/10.1177/1043463108099349

[94] Barb Ruppert. 2011. New directions in the use of virtual reality for food shopping: Marketing and education perspectives. F. Diabetes Sci. Technol. 5, 2 (2011), 315-318. DOI: https://doi.org/10.1177/193229681100500217

[95] Stuart Russell. 2016. Should we fear supersmart robots? Sci. Am. 314, 6 (2016), 58-59. D0I:https://doi.org/10.1038/ scientificamerican0616-58

[96] Richard M. Ryan and Edward L. Deci. 2006. Self-regulation and the problem of human autonomy: Does psychology need choice, self-determination, and will? f. Pers. 74, 6 (2006), 1557-1586. DOI : https://doi.org/10.1111/j.1467-6494.2006.00420.x

[97] Jeroen Schepers and Martin Wetzels. 2007. A meta-analysis of the technology acceptance model: Investigating subjective norm and moderation effects. Inf. Manag. 44, 1 (2007), 90-103. DOI : https://doi.org/10.1016/j.im.2006.10.007

[98] F. David Schoorman, Roger C. Mayer, and James H. Davis. 2007. An integrative model of organizational trust: Past, present, and future. Acad. Manage. Rev. 32 (2007), 344-354. DOI: https://doi.org/10.5465/AMR.2007.24348410

[99] Lijiang Shen and James Price Dillard. 2005. Psychometric properties of the Hong psychological reactance scale. 7. Pers. Assess. 85, 1 (2005), 74-81. DOI: https://doi.org/10.1207/s15327752jpa8501_07

[100] Keng Siau and Weiyu Wang. 2018. Building trust in artificial intelligence, machine learning, and robotics. Cut. Bus. Technol. F. 31, 2 (2018), 47-53.

[101] Nicholas F. Skinner, John A. Giokas, and Henry A. Hornstein. 2006. Personality correlates of Machiavellianism: 1. Consensual validation. Soc. Behav. Personal. Int. 7. 4, 2 (2006), 273-276. DOI : https://doi.org/10.2224/sbp.1976.4.2.273

[102] Matthew B. Sparke. 2006. A neoliberal nexus: Economy, security and the biopolitics of citizenship on the border. Polit. Geogr. 25, 2 (2006), 151-180. DOI : https://doi.org/10.1016/j.polgeo.2005.10.002

[103] Nicolas Spatola, Clément Belletier, Pierre Chausse, Maria Augustinova, Alice Normand, Vincent Barra, Ludovic Ferrand, and Pascal Huguet. 2019. Improved cognitive control in presence of anthropomorphized robots. Int. F. Soc. Robot. 11, 3 (2019), 463-476. DOI : https: //doi.org/10.1007/s12369-018-00511-w

Digital Government: Research and Practice, Vol. 2, No. 3, Article 26. Publication date: July 2021. 
[104] Nicolas Spatola, Clément Belletier, Alice Normand, Pierre Chausse, Sophie Monceau, Maria Augustinova, Vincent Barra, Pascal Huguet, and Ludovic Ferrand. 2018. Not as bad as it seems: When the presence of a threatening humanoid robot improves human performance. Sci. Robot. 3, 21 (2018), eaat5843. DOI: https://doi.org/10.1126/scirobotics.aat5843

[105] Nicolas Spatola and Karolina Urbanska. 2019. God-like robots: The semantic overlap between representation of divine and artificial entities. AI Soc. 35, (2019), 329-341. DOI : https://doi.org/10.1007/s00146-019-00902-1

[106] Dag Sverre Syrdal, Kerstin Dautenhahn, Kheng Lee Koay, and Michael L. Walters. 2009. The negative attitudes towards robots scale and reactions to robot behaviour in a live human-robot interaction study. In Proceedings of the 23rd Convention of the Society for the Study of Artificial Intelligence and Simulation of Behaviour: Adaptive and Emergent Behaviour and Complex Systems (AISB'09), 109-115.

[107] Tom R. Tyler, Kenneth A. Rasinski, and Kathleen M. McGraw. 1985. The influence of perceived injustice on the endorsement of political leaders. F. Appl. Soc. Psychol. 15, 8 (1985), 700-725. DOI : https://doi.org/10.1111/j.1559-1816.1985.tb02269.x

[108] David Valle-Cruz, Rodrigo Sandoval-Almazan, Edgar A. Ruvalcaba-Gomez, and J. Ignacio Criado. 2019. A review of artificial intelligence in government and its potential from a public policy perspective. In Proceedings of the ACM International Conference Proceeding Series, 91-99. DOI : https://doi.org/10.1145/3325112.3325242

[109] Viswanath Venkatesh, Michael G. Morris, Gordon B. Davis, and Fred D. Davis. 2003. User acceptance of information technology: Toward a unified view. MIS Q. Manag. Inf. Syst. 27, 3 (2003), 425-478. DOI : https://doi.org/10.2307/30036540

[110] Vipasiri Vimonses, Shaomin Lei, Bo Jin, Chris W. K. Chow, and Chris Saint. 2009. Adsorption of congo red by three Australian kaolins. Applied Clay Science 43, 3-4 (2009), 465-472. DOI : https://doi.org/10.1016/j.clay.2008.11.008

[111] Steven Van de Walle, Steven Van Roosbroek, and Geert Bouckaert. 2008. Trust in the public sector: Is there any evidence for a long-term decline? Int. Rev. Admin. Sci. 74, 47-64. DOI : https://doi.org/10.1177/0020852307085733

[112] Bernard Williams. 2000. Formal structures and social reality. In Trust: Making and Breaking Cooperative Relations, Diego Gambetta (Ed.). University of Oxford, Oxford, 3-13.

[113] Bogdan Wojciszke and Bozena Klusek. 1996. Moral and competence-related traits in political perception. Pol. Psychol. Bull. 27, 1 (1996), 319-325.

[114] Phil Wood. 2008. Confirmatory factor analysis for applied research. The American Statistician 62, 1 (2008), 91-92.

Received June 2020; revised December 2020; accepted January 2021

Digital Government: Research and Practice, Vol. 2, No. 3, Article 26. Publication date: July 2021. 